\title{
Transformação do Contrato Psicológico no Contexto da Privatização: Estudo de Casos
}

\author{
Ursula Wetzel
}

\section{RESUMO}

Este estudo descreve a transformação do contrato psicológico no caso de duas empresas brasileiras, do setor de serviços, privatizadas no biênio 1997-1998. Os dados foram coletados por meio de 42 entrevistas em profundidade, realizadas em dois Estados da Região Sul e em um Estado da Região Sudeste. As entrevistas foram realizadas entre os diversos níveis hierárquicos das empresas e incluíram 2 diretores de recursos humanos, 17 gerentes de nível médio e 23 funcionários de nível administrativo e operacional. A análise utilizou o modelo proposto por Rousseau (1996), que identifica quatro estágios na transformação do contrato psicológico: (1) ameaça ao contrato antigo; (2) preparação para a mudança; (3) criação de novo contrato; e (4) vivência no novo contrato. De acordo com a pesquisa, contratos psicológicos, ao serem renegociados, requerem o entendimento não apenas dos aspectos relativos às promessas - implícitas ou explícitas - percebidas pelos funcionários, mas também de outros pontos externos ao contrato, como a confiança preexistente na relação empregador-empregado, a mudança do ambiente externo (concorrência, mercado de trabalho) e a mudança do ambiente interno (cultura organizacional, tecnologia adotada).

Palavras-chaves: contrato psicológico; gerência de mudanças; recursos humanos.

\begin{abstract}
This study describes the transformation of the psychological contract in two service companies privatized in the years of 1997 and 1998. Data were collected through 42 in-depth interviews in two states in the South and one state in Southeast Brazil. Interviews occured in all hierarchical levels, including 2 human resources top managers, 17 middle managers and 23 white and blue collar employees. According to Rousseau (1996)'s model, four stages of the transformation process were identified: (1) challenging of the old contract; (2) preparation for change; (3) new contract generation; and (4) living in the new contract. According to the study, transformation of the psychological contract requires not only understanding those aspects related to explicit or implicit promises, but also aspects external to the contract such as trust, changes in the firm's external environment (competition, labor market), and changes in the internal environment (organizational culture, technology).
\end{abstract}

Key words: psychological contract; change management; human resources. 


\section{INTRODUÇÃO}

As empresas, na busca por maior agilidade e menores custos, têm passado por mudanças as mais variadas: venda de unidades menos produtivas, compra de outras empresas, alianças com concorrentes, enxugamento da estrutura interna, para citar apenas algumas. Nem mesmo o Governo Federal escapou desse movimento. O Programa Nacional de Desestatização, com a venda de empresas para a iniciativa privada, procurou fomentar investimentos nas atividades em tela, dar mais agilidade e eficiência operacional às empresas além de, paralelamente, desonerar o governo.

A passagem, entretanto, de uma empresa do âmbito estatal para o privado implica sujeição a novo ambiente de negócios, reestruturações internas e renegociações com funcionários, renegociações essas que incluem não apenas o contrato formal, mas também o contrato implícito de deveres e obrigações de ambas as partes.

O presente trabalho visa a estudar o processo de transformação do contrato psicológico no caso de duas empresas brasileiras privatizadas no biênio 199798, ao passarem da condição de empresa estatal para empresa privada.

\section{Contrato Psicológico}

Contrato psicológico é o contrato implícito, não formal, que ocorre, segundo a percepção do empregado, entre a organização e o funcionário, referente às promessas de direitos e obrigações de cada uma das partes. Trata-se de uma "crença acerca dos termos e condições de um acordo do qual o indivíduo faz parte" (Robinson, 1995, p. 92) e tem por base as percepções e as crenças, por parte do empregado, acerca do que são as promessas de obrigações mútuas.

Contratos psicológicos são classificados tendo por base as trocas esperadas entre as partes. Duas categorias de contratos são consideradas na literatura: contratos transacionais e contratos relacionais (Robinson, Kraatz e Rousseau, 1994; Robinson, 1995; Herriot e Pemberton, 1996). São ditos transacionais os contratos de caráter instrumental, em que as trocas são específicas e quantificáveis, geralmente do tipo oferecimento de serviço em troca de valores monetários. Contratos com termos de desempenho menos específicos, que incluem trocas 
monetárias ou não, mas que geram uma expectativa de longo tempo de associação com a empresa, acompanhados de fatores que vão além de aspectos profissionais como a lealdade e o apoio, são classificados como relacionais (Robinson, Kraatz e Rousseau, 1994; Morrinson e Robinson, 1997).

\section{Rompimento do Contrato Psicológico}

$\mathrm{O}$ contrato mantém-se vigente enquanto as partes cumprem ou excedem os termos do acordo. A percepção de que houve violação contratual depende, segundo Robinson (1996), em primeira instância, de o empregado perceber uma quebra no contrato e, em segunda instância, da interpretação dada a esta quebra. Segundo a autora, muitas vezes acordos são rompidos sem que o empregado o perceba; mesmo se confirmada cognitivamente, a percepção de violação está vinculada à interpretação dos fatos. Fatores como confiança na relação com o empregador e tipo de contrato psicológico podem impedir que aflore um sentimento de violação contratual.

Violações em contratos transacionais geram no empregado uma sensação de que seus benefícios foram reduzidos, podendo produzir sentimentos de injustiça e traição. Por ter um caráter de troca econômica, o empregado tenta reequilibrar a situação, entendendo que suas obrigações em relação ao empregador são, agora, menores (Robinson, Kraatz e Rousseau, 1994; Herriot e Pemberton, 1996).

Violações em contratos relacionais, por sua vez, podem implicar a mudança da própria natureza da relação. Por envolver fatores emocionais como confiança, crença na boa vontade e tratamento justo, a violação pode desgastar as obrigações mais centrais nesse tipo de relacionamento. $\mathrm{O}$ empregado sente-se desobrigado da lealdade e dos esforços extras, uma vez que as dimensões relacionais do contrato não mais são válidas (Robinson, Kraatz e Rousseau, 1994). Nesse caso, sentimentos de pesar, desconfiança e raiva podem provocar uma renegociação do contrato em bases puramente transacionais (Organ apud Herriot e Pemberton, 1996). Se, no entanto, os contratos são percebidos como justos e equânimes, a tendência é de que se desenvolvam relações mais próximas, em que as partes oferecem benefícios mútuos acima dos termos acordados inicialmente (Herriot e Pemberton, 1996).

Acordos violados afetam, portanto, a confiança; esta se relaciona com o declínio na qualidade da comunicação e cooperação, do processo decisório e desempenho. Se algum dos pontos esperados da relação se referir a aspectos de trabalho, então uma violação implica que o empregado terá menos motivos para dele 
obter satisfação. Ao entender que a empresa não valoriza sua contribuição, poderá incorrer em comportamentos de absenteísmo, declínio de atitudes positivas em relação à organização e mesmo troca de emprego (Robinson, 1995).

\section{Renegociação do Contrato Psicológico}

A grande pressão competitiva tem levado as empresas a romperem parte do acordo psicológico que governava suas relações com os empregados. Diante de mudanças, torna-se necessária uma renegociação do contrato psicológico (Robinson, 1995).

A mudança e renegociação de um contrato psicológico podem ser realizadas por meio de duas estratégias: acomodação e transformação. Na acomodação, os termos do contrato são "modificados, clarificados, substituídos ou expandidos" (Rousseau, 1996, p. 50), permanecendo-se, porém, dentro do espírito do antigo contrato.

$\mathrm{Na}$ transformação, as mudanças são radicais e espera-se que todo um novo conjunto de expectativas passe a vigorar (Rousseau, 1996). Incluem-se, por exemplo, questões mais localizadas, como nova forma de trabalhar (multifuncionalidade, responsabilidade sobre a tarefa, trabalho em equipe), bem como questões mais amplas, como o direito e a garantia ao emprego.

A transformação do contrato psicológico, se bem conduzida, pode levar a uma nova base de relacionamento e comprometimento. Se mal conduzida, será percebida como violação do estabelecido, com conseqüências negativas para a empresa. Mudar esse contrato não tem sido fácil tarefa e, segundo alguns executivos, algumas pessoas, notadamente os empregados mais antigos, ficaram "emocionalmente e intelectualmente bloqueadas" (O’Reilly, 1994, p. 30).

Rousseau (1996) sugere que a modificação do contrato psicológico se ampare na teoria do processo psicológico de busca de informações, indicando que informações antigas devem ser descongeladas antes que um novo quadro mental possa ser criado. A autora propõe, assim, um processo em quatro estágios.

Ameaça ao contrato antigo. Neste estágio as bases do contrato vigentes são questionadas e sofrem ameaça. É preciso, entretanto, que as razões que afetam a mudança do contrato sejam percebidas, por parte dos empregados, como legítimas. 
- Preparação para a mudança. Nesta fase os sinais da mudança se fazem presentes. As pessoas sentem que o antigo contrato deixa de vigorar e formam-se as bases para um novo relacionamento. Três aspectos são importantes neste estágio: sinais e ações simbólicas de que o velho contrato acabou, compreensão de que neste estágio as perdas percebidas são maiores do que os ganhos futuros e implantação, se necessário, de estruturas e esquemas transitórios para facilitar a mudança.

. Criação de novo contrato. Esta é a hora em que o futuro deve orientar as expectativas, ações e compromissos. Premissas do passado deixam de vigorar; empregados antigos devem comportar-se, no que se refere às regras da empresa, como se fossem empregados novos.

- Vivência no novo contrato. Nesta etapa o novo contrato sofre alguns testes. A empresa deve mostrar, mediante ações e comunicações consistentes, que não há volta possível ao modo antigo de ser e pensar.

\section{Metodologia}

A pesquisa utilizou o método de estudo de casos, investigando a realidade de duas empresas desestatizadas dentro do Programa Brasileiro de Privatização. O método de casos é considerado adequado, quando se está interessado em obter dados em profundidade e com muitos detalhes acerca de um determinado assunto (Gil, 1987). Para Yin (1984) estudos de casos são adequados, quando a pergunta da pesquisa é do tipo por que ou como, e o fenômeno a ser estudado, além de contemporâneo, não permite ao pesquisador qualquer tipo de controle sobre ele. Ainda segundo o autor, o método se aplica aos casos em que fenômeno e contexto não são facilmente distinguíveis (Yin, 1993). Há que apontar entretanto que, por não se estar tratando de representatividade estatística, não há como generalizar os resultados da pesquisa. Em verdade o estudo de dois casos traz em si a limitação de não se ter certeza se são, realmente, representativos do universo (Gil, 1987).

O principal meio de coleta de dados adotado foi a entrevista em profundidade, pois esta permite identificar o que a outra pessoa pensa, dando acesso a "sentimentos, pensamentos e intenções" (Patton, 1980, p. 6). Pelo relato pode-se saber como o ator organiza e atribui significado ao processo no qual está ou esteve envolvido. As entrevistas basearam-se em roteiro semi-estruturado, o que permitiu obter pontos de vista diferentes acerca das mesmas questões, sem impedir que novos aspectos e considerações (insights) surgissem. 
Os dados foram coletados em 42 entrevistas em profundidade, abrangendo vários níveis hierárquicos. Na caso da primeira empresa, com sede na Região Sudeste, entrevistou-se o diretor de recursos humanos, 8 gerentes em nível médio e 12 funcionários administrativos e operacionais. No caso da segunda empresa, com sede na Região Sul, foram realizadas, igualmente, 21 entrevistas em profundidade, incluindo o diretor de recursos humanos, 9 gerentes em nível médio e 11 funcionários administrativos e operacionais lotados em dois Estados diferentes.

A duração média das entrevistas foi de uma hora, resultando um total de 42 horas de gravação e cerca de 800 páginas de transcrição. Os textos foram analisados com auxílio do software para análise qualitativa Nud*ist. A análise dos dados consistiu em três etapas. Na primeira delas elaborou-se uma lista de conceitos com base na revisão de literatura. A segunda etapa consistiu na codificação das entrevistas, permitindo a emergência de novos conceitos e o refinamento daqueles já existentes. Nessa tarefa, o software revelou-se particularmente útil, por facilitar o processo interativo característico desta fase. Finalmente, procedeu-se à análise dos conceitos em sua forma já quase final. Esta etapa caracterizou-se por ocorrer em dois níveis simultâneos: o global e o do detalhe. Navegou-se entre dois mundos: o do balão e o da lupa. No primeiro, o do balão, pôdese adquirir uma visão mais geral do conceitos; no segundo, o da lupa, verificouse no detalhe a confirmação da visão geral previamente adquirida. Este duplo olhar permitiu que a síntese dos dados emergisse, naturalmente, da riqueza do detalhe.

\section{Os Estudos de CAso}

\section{A Empresa ServA}

A ServA, estatal do setor de serviços com sede na Região Sudeste, era tida, dentro de seu âmbito de atuação, como empresa modelo. As demais empresas estaduais do mesmo setor estavam longe de atingir o seu nível de desempenho, ao ponto de, quando houve a privatização, ser considerada um benchmark nacional, tanto em termos gerenciais quanto em termos técnicos e operacionais.

Em 1996, já se preparando para a iminente privatização de todo o setor, a empresa ofereceu um primeiro Plano de Desligamento Incentivado (PDI), que obedecia a determinadas regras impostas pela diretoria. Em 1998, a empresa foi vendida, junto com outras empresas do mesmo setor. A ServA passou a fazer 
parte de um grupo maior, cuja holding se localizava na Região Sudeste, junto com outras empresas estaduais igualmente privatizadas.

As diretrizes passaram, portanto, a ser dadas, deste momento em diante, pela holding. Inclusas nestas diretrizes estavam as questões referentes aos recursos humanos e, mais especificamente, à questão de implantação de um plano de demissão.

De acordo com o edital de concessão, qualquer demissão em massa dentro dos primeiros 180 dias da privatização, deveria ser feita na forma de um plano de desligamento incentivado, sendo que a empresa teria total liberdade para estabelecer os critérios do plano.

A holding optou, após várias análises e simulações de custo, por realizar um plano de desligamento ainda dentro dos seis meses iniciais, plano esse que tinha por principais características: (1) o pagamento de incentivo financeiro proporcional ao número de anos de serviço, estimulando aqueles que tivessem maior tempo de empresa; (2) a manutenção do plano de assistência médica por mais 90 dias; e (3) uma cesta básica, que poderia ser convertida em dinheiro.

Assim, o desenho do plano foi idealizado pela matriz que o implantou em todas as empresas componentes do grupo. Algumas decisões ficaram, entretanto, a cargo das unidades. No caso da ServA, a principal decisão referiu-se à questão da possibilidade de se recusar uma adesão. A empresa optou por aceitar todos os pedidos de desligamento, não havendo nenhuma ação para reter pessoas consideradas estratégicas ou tidas como talentos, por considerar que, ao recusar um pedido de saída, passaria a ter que dar uma reciprocidade não comportada pelos planos de recursos humanos. Nas palavras do diretor de recursos humanos da unidade:

"o plano tinha uma remuneração até bem atrativa para quem fosse sair. Então, na medida em que você não deixasse a pessoa sair, e ela continuava a trabalhar, continuava com o seu salário, ela iria falar: 'E agora? Eu fico e você não quer deixar eu sair. Mas o que eu vou ganhar?' Vai continuar trabalhando no mesmo lugar e ganhando a mesma coisa, enquanto para sair ia ganhar tantos mil reais".

A ServA por estar, entre as demais empresas formadoras da nova holding, em estágio tecnológico mais avançado, utilizou-se de meios eletrônicos para a comunicação do plano. O processo foi comunicado por meio de terminais de computadores, onde os empregados podiam obter os dados relativos ao seu processo. A adesão foi, também, realizada pelo terminal. Nas palavras dos entrevistados, "bastava um enter" para se aderir ao plano. 
Como resultado final, o plano contou com a adesão de 1.074 pessoas, com idade média de 47 anos e média de 22 anos trabalhados na empresa. Na avaliação do diretor de recursos humanos, esta adesão foi surpreendente, pois se esperava, em função de simulações realizadas, um volume bem menor, em torno de 700 a 800 adesões.

\section{As Etapas de Renegociação do Contrato Psicológico}

- Ameaça ao antigo contrato. Sem dúvida os primeiros sinais de mudança surgiram com o próprio programa de privatização. Muito mais do que passar o controle acionário do governo para a iniciativa privada, a privatização veio carregada de significados simbólicos, que a fizeram objeto de temor, de um lado, e de esperanças, de outro.

A questão mais importante, sem dúvida, que se configurava na cabeça dos entrevistados, era a estabilidade do emprego. Havia uma consciência de que as práticas de retenção de emprego das empresas privadas seriam diferentes daquelas das estatais. Assim, para algumas pessoas, a privatização era sinônimo de demissão.

"Qual é o grande temor da privatização? Na visão de quem está dentro de uma estatal, é perder o emprego. [...] Então o sinalizador mais forte das pessoas era que a privatização significaria, num primeiro momento, perda do emprego" (funcionário de área administrativa).

Para outros, a privatização representava oportunidades que não estavam disponíveis na empresa estatal, como, por exemplo, o desenvolvimento de novos projetos e, mesmo, a possibilidade de uma promoção.

"Eu acho que ela dá muito mais oportunidade às pessoas delas mostrarem aquilo que aprenderam, o desenvolvimento que tiveram durante o seu período de vida" (funcionário de área operacional).

- Preparação para a mudança. A administração da ServA, consciente de que o processo de privatização seria inevitável, iniciou um trabalho de preparação dos funcionários, que se concretizou com uma série de palestras ministradas na capital e em várias localidades do interior do Estado.

"Essa preparação veio através de vários treinamentos que nós recebemos, através de várias palestras que nós tivemos, através de vários seminários [...] em que se envolveram várias empresas da iniciativa privada" (funcionário de área operacional).

Ações individuais das chefias, no sentido de conscientizar os funcionários da privatização iminente, estiveram também presentes. 
"Eu atuei na função gerencial e com o grupo conversava muito sobre essas coisas, exatamente para as pessoas entenderem de que essa coisa estatal e privatização tem algo muito mais complexo por trás disso tudo, que é o sistema capitalista" (funcionário de área administrativa).

Se, de uma forma geral, não se acreditava na privatização, ainda assim algumas pessoas, preocupadas com seu futuro, empreenderam ações que as tornariam mais bem preparadas para o futuro.

"Então o pessoal começou a fazer curso de inglês, curso de espanhol, ou fazer um curso a mais de extensão, procurar aprimorar seus conhecimentos" (gerente).

Uma vez privatizada, a empresa ofereceu um plano de desligamento incentivado a todos os seus funcionários. A implantação deste plano de redução de pessoal foi percebida por seus funcionários a partir de várias óticas. $\mathrm{O}$ entendimento mais comum foi o da necessidade de redução de custos com o objetivo de chegar ao nível de gastos de uma empresa concorrente do mesmo ramo.

"Na minha opinião, é porque o custo de pessoal, comparativamente com empresas semelhantes, estava muito alto. Então, por que ela fez? Pela necessidade de já ir trabalhando na redução de custos, dentro do enfoque de se preparar para o mercado competitivo, para se tornar uma empresa competitiva" (funcionário de área administrativa).

Havia, de uma forma geral, o entendimento de que a ServA se deparava com cenário de negócios substancialmente diferente daquele que enfrentara como estatal. Do ponto de vista do meio ambiente, vários eram os desafios a serem enfrentados. De um lado, a entrada de concorrentes diretos em seu ramo de atuação; de outro, a entrada de novas tecnologias, as quais não dominava e que poderiam substituir a forma mais tradicional de atender o cliente.

Quando monopolista, em mercado com elevada demanda, a empresa não via necessidade de vender o seu produto. Na nova configuração ambiental, teria de concorrer com outras na conquista do cliente e na manutenção de sua rentabilidade.

"A questão é que se precisava fazer um ajuste. Os números da empresa, comparados com números internacionais [...] estava acima e existia a necessidade de fazer essas adequações. Nesse mercado competitivo que a gente está enfrentando já, e vai enfrentar, as empresas que não tiverem demitido não vão realmente conseguir colocar o serviço no mercado a um preço competitivo. A parte de custos com pessoal é um fator importante" (gerente). 
. Criação de um novo contrato. Algumas mudanças foram configurando-se depois que a empresa foi privatizada. As maiores mudanças relatadas referem-se à perda de segurança no emprego, maior cobrança, maior carga de trabalho, acompanhada de muitas horas extraordinárias de trabalho.

"O número de horas que eu trabalho hoje é muito maior. O grau de acuidade das informações [...] é muitíssimo maior. O nível de controle que a gente tem sobre o processo, sobre as informações é infinitamente maior. A cobrança é muito maior, a paciência é zero, para errar é zero" (gerente).

- Vivência no novo contrato. Dois aspectos ressaltam na vivência do novo contrato de trabalho: a certeza de que a estabilidade do emprego estava para sempre perdida e a manutenção da confiança na empresa.

"Alterou [a questão da estabilidade]. Não só alterou, como as pessoas já botaram na cabeça que está alterado. [...] Até então era a mãe estatal: ela vai, no máximo, puxar as orelhas [...] não vai me botar na rua. Após a privatização, já se sentiu que, independente de plano de redução de pessoal, houve demissões. Antes do plano, depois do plano, continua havendo demissões" (gerente).

Se de um lado havia o entendimento de que a estabilidade do emprego estava perdida, ainda assim as mudanças não foram suficientes para abalar a crença de que aquela era uma boa empresa para nela se trabalhar. Não se pode esquecer que as pessoas entrevistadas tiveram a oportunidade de aderir ao plano de desligamento voluntário, mas não o fizeram, apostando que a melhor alternativa seria, apesar de tudo, continuar na empresa. Outros fatores parecem ter contribuído para a permanência, como, por exemplo, a expectativa de, no futuro, ter direito à complementação de aposentadoria, a satisfação com o trabalho realizado e a situação de desemprego do mercado de trabalho.

"A situação que vivemos, não é de agora, neste país, a questão do desemprego. Você está bem, está empregado, está prestigiado, está fazendo um trabalho que você gosta; não tinha sentido, não tinha por que você pensar num desligamento" (funcionário de área administrativa).

\section{A Empresa ServB}

Trata-se de empresa prestadora de serviços com âmbito de atuação na Região Sul do país. Seguindo o Programa Brasileiro de Privatização, foi adquirida, em 1997, por um consórcio de sócios majoritariamente nacionais.

Ainda como estatal e tendo em vista a preparação para a privatização, a empresa ofereceu, no final de 1996, um plano de demissão voluntária que, embora tivesse 
sido oferecido a todos os empregados, mantinha a prerrogativa de a empresa aceitar ou não o pedido de desligamento. Em verdade, dadas as restrições orçamentárias na época, estabeleceu-se uma cota para as adesões e nem todos os que se inscreveram puderam participar do plano.

Ao ser anunciado o ganhador do leilão de privatização no final de 1996, iniciou-se uma fase de transição, com cerca de dois meses de duração, em que se realizou uma administração conjunta da estatal e do consórcio adquirente. Nessa época, os novos administradores montaram uma equipe responsável pela transição, que definiu, entre outras coisas, as linhas da nova estrutura administrativa e, também, um novo plano de demissão a ser imediatamente implantado.

No início de 1997, finalmente, a nova diretoria assumiu, realizando, logo no primeiro dia, um grande volume de demissões, com cerca de 2.000 pessoas dispensadas. Para que esse contingente pudesse ser selecionado, coube à nova administração proferir palestras aos gerentes no sentido de prepará-los para o processo de demissão a ocorrer. Nas palavras do diretor de recursos humanos:

"nós fizemos palestras em toda a empresa, preparando essas pessoas (os líderes) para o processo de demissão. Que muitos desses nunca demitiram uma só pessoa. [...] Então nós tivemos de fazer um trabalho de preparação: que a demissão era uma coisa necessária e ela viabilizava a empresa. Sem as demissões a empresa era inviável. [...] Então nós preparamos os líderes para o processo de demissão".

Esse não foi o único movimento de redução de pessoal. Ao longo de 1997 e de 1998 outras reduções substanciais foram realizadas, uma com cerca de 500 e outra com cerca de 600 funcionários desligados.

Toda uma nova forma de trabalhar foi implantada na empresa. Fez-se um forte investimento em informática na empresa. As pessoas receberam treinamento em microcomputação e em novos sistemas de gestão e automação. Além disso, muitas atividades foram também terceirizadas.

\section{As Etapas de Renegociação do Contrato Psicológico}

. Ameaça ao contrato antigo. O processo de privatização chegou paulatinamente ao conhecimento dos funcionários da empresa. Rumores sobre a possibilidade de privatização iniciaram-se anos antes da concretização real do fato.

"Começou falando bem pouquinho e tal, vagarosamente. A gente até não ligava muito ou não dava muita importância na época, porque parecia uma coisa que era falada, mas que, na verdade, não ia acontecer. Pelo 
menos para a gente. A gente sempre acha que nunca muda nada. Então dava a impressão que no começo [...] E, na verdade, eu só comecei a me dedicar mais, a ler mais sobre as privatizações, quando realmente eu vi que ia acontecer. Então eu tentei estudar mais e aprender um pouquinho mais sobre a privatização. [...] Mas, de início, eu não me incomodei muito com isso não" (funcionário de área operacional).

A compreensão da proximidade do fato era alimentada por notícias nos jornais e pela intensificação nos rumores internos. Havia, também, uma carência de informação por parte da direção da empresa. Os funcionários ressentiam-se de falta de informação oficial e mesmo a atuação do sindicato era percebida como precária. Como, para a maior parte dos respondentes, a estatal havia sido seu único ou principal emprego, havia da parte deles uma falta de experiência com empresas privadas. Em seu imaginário, a empresa privada iria demitir a todos e trabalharia primordialmente com empresas terceirizadas.

"Aí depois veio aquela história de privatização: ia ser privatizado. Aí você fica naquela, não sabe o que vai ser. Sempre todo mundo comentava: vai um monte de gente para a rua, isso aí com certeza. Isso aí a gente tinha certeza de que muita gente iria" (funcionário administrativo).

Numa visão retrospectiva, os entrevistados relatam as regras de relacionamento na estatal. Em uma perspectiva bastante geral, a estatal era vista como uma organização em que era difícil demitir alguém e com igualdade na remuneração dos funcionários, independentemente de sua produtividade.

"O plano de cargos e salários e de merecimento era igual para todos. Se você fosse um bom funcionário ou fosse ruim, você recebia a mesma coisa. Não tinha meritocracia. [...] Você não era reconhecido e eu também não, tudo bem, ficava por isso mesmo".

. Preparação para a mudança. Durante o ano de 1996 a privatização assumiu contornos mais nítidos e mais sólidos. Nesta época a empresa estatal ofereceu um plano de demissão voluntária que, de certa forma, tangibilizou as mudanças vindouras. Nessa época os gerentes intermediários viram-se no difícil papel de motivar seus funcionários a despeito da falta de informações e da insegurança que estava no ar. Alguns começaram a preparar seus funcionários para uma nova gama de valores organizacionais, tendo como foco central a questão de que a manutenção do emprego estaria ligada à produtividade e ao valor individual de cada empregado.

"Então eles tinham esse temor (de serem demitidos) e o que a gente sempre disse, para poder manter o pessoal, é que se houvesse espaço para alguém trabalhar, sempre iria ser para os melhores. [...] E o que aconteceria? Isso 
a gente não sabia. Isso era uma coisa que a gente não tinha conhecimento, podia até imaginar" (gerente).

A sinalização mais forte, porém, de que as regras se estavam transformando, veio na forma de um plano de demissão, em que cerca de 2.000 pessoas foram demitidas no primeiro dia de gestão oficial da nova empresa. Esta demissão sinalizou, de forma muito clara, que a estabilidade de emprego que vigorava na estatal era, agora, coisa do passado. Nas palavras de um funcionário da área de recursos humanos, que tinha acesso às listas de demissão, mas que, assim mesmo, não sabia se seria despedido ou não:

"eu tinha todas as listas de demissões. [...] Nós éramos três pessoas [...] tínhamos essas informações de todas as áreas. Começamos a preparar as cartas de demissão [...] Nada me garantia que meu nome não estivesse [em outra lista], que eu não tivesse sido comunicado".

- Criação de um novo contrato. Terminada a fase de transição de estatal para privada, a própria forma de administração dos novos donos permitiu a elaboração das novas regras e do novo contrato de trabalho. Os depoimentos dos empregados apontam para questões como maior responsabilidade e autonomia sobre a tarefa, acompanhada, ainda, de forte cobrança dos resultados.

"É estressante porque ela (a empresa) transferiu muita responsabilidade para os líderes, para mim, para a turma da oficina. Aquela responsabilidade que não tinha em 97. Os líderes eram líderes, mas tinha mais gente para definir. Hoje não, hoje eles transferiram mais para nós, e nós decidimos mais as coisas" (funcionário de área operacional).

Instalou-se, ainda, a cultura da multifuncionalidade, a valorização do desempenho pessoal e a abertura na comunicação vertical. Todas essas práticas contrastam fundamentalmente com aquelas da época de estatal, que operava com grande divisão de tarefas, responsabilidade e autonomia limitadas, sem preocupação com a cobrança dos resultados, além de adotar uma comunicação restrita à hierarquia.

"Hoje as coisas vão mais rápido. Por quê? Se eu preciso resolver algum assunto, eu ligo para a secretária do diretor de R.H., digo: 'Eu preciso marcar uma hora que eu preciso resolver um assunto com ele' . [...] Ele me atende. Na estatal já era mais difícil, porque você tinha de respeitar muito, a hierarquia era muito rígida" (funcionário de área administrativa).

No relato dos entrevistados, cumpre destacar, é freqüente o sentimento de valorização das pessoas pela nova administração. A contrapartida a essa valorização, no entanto, é percebida como tendo um alto preço. 
"Na empresa o presidente faz questão de ir lá e conversar ele mesmo. Viaja, usa uniforme, ele se aproxima bastante dessas pessoas, ouve muito as pessoas. [...] Mas, ao mesmo tempo, há uma cobrança muito grande em relação às normas, às responsabilidades. Então, se você for me perguntar sobre a distância entre a chefia e o empregado lá de baixo, ela era muito grande. Mas a cobrança era proporcionalmente menor. Quando você deu essa oportunidade, muito maior, do presidente chegar ao funcionário e falar ou ligar e conversar, a responsabilidade aumentou tanto que, talvez, essa relação entre uma coisa e outra, responsabilidade e facilidade de você conversar, seja de uma outra dimensão" (gerente).

A avaliação e conseqüente valorização das pessoas baseia-se, na nova organização, em abandono da supervalorização das realizações passadas em prol de um comprometimento com realizações futuras. O mérito principal está naquilo que é e pode ser realizado para a frente. $O$ discurso da meritocracia pregado pela nova administração contrasta, portanto, substancialmente, com a avaliação em tempos de estatal.

"Hoje a empresa tem uma política de meritocracia. Você propõe as coisas, elas são analisadas e, se elas forem boas, com certeza serão implantadas. E você é medido por isso, por esse retorno que você dá. [...] O nosso diretor de R.H. diz que a gente é medido não pelo que já fez, e sim pelo que pode fazer ainda. Mas o que você fez, está feito. 'Muito bom, muito legal, mas interessa o que a gente pode fazer daqui para a frente"' (gerente).

Certamente a maior mudança se refere à estabilidade do emprego. Enquanto na época de estatal havia quase uma impossibilidade de alguém ser demitido, na nova organização há uma consciência muito clara da fragilidade do emprego. Os requisitos para a permanência atingem um leque amplo, e incluem a necessidade de mostrar produtividade, de estar constantemente se desenvolvendo, de estar alinhado com os objetivos da organização, de estar comprometido e de estar no espírito da empresa privada. De forma geral, os funcionários entendem que o seu emprego não está absolutamente assegurado e que nem mesmo um bom desempenho é garantia suficiente para a sua manutenção.

"O dia em que eu parar de trabalhar, o dia em que parar de ser dedicado, o dia em que eu resolver trabalhar só as minhas oito horas, eles vão me mandar embora. Enquanto eu estiver trabalhando nas minhas 12 horas, 13 horas, 2 ou 3 de graça, estou legal. Mas o dia em que (alguém disser): 'A partir de hoje só vou trabalhar das 7 às 11 e do meio dia às 15, ganho para isso, a minha carteira está assinada assim, não quero conversa.', o camarada não vai servir mais para eles. A verdade é essa" (funcionário de área operacional). 
Outra mudança refere-se à preocupação em relação aos custos da empresa, ao atingimento de metas e ao desempenho global da empresa. Todas essas preocupações são devidamente sinalizadas na organização. Em cada local de trabalho a empresa expõe um quadro com a lista de metas do setor e uma avaliação do atingimento delas. Mesmo a diretoria e a presidência exibem seus quadros. E essa preocupação reflete-se no discurso dos empregados.

"Eu acho que hoje ninguém está seguro cem por cento. Mas também não está em nenhuma empresa privada. Eu acho que não se tem segurança. Mas hoje nós temos metas bem definidas, nós sabemos o que a empresa pensa como um todo, e nós sabemos o que nós devemos fazer para tentar conseguir atingir essas metas da empresa. [...] Então isso dá um horizonte para você tentar" (funcionário de área administrativa).

- Vivência no novo contrato. Pode-se dizer que após dois anos e meio de privatização a empresa obteve sucesso na renegociação do contrato psicológico. As práticas da estatal estão na memória das pessoas, mas não fazem mais parte do seu elenco de expectativas. A questão da vulnerabilidade do emprego está plenamente incorporada ao contrato psicológico, sendo reforçada pela comparação com outras empresas do mercado, gerando certo consolo do tipo é assim também em outras empresas.

"Eu acho que depende da cabeça de cada um. Acho que nessa parte da insegurança, pelo que eu vejo, que vou ter de conviver com ela enquanto estiver aqui dentro, vou ter de conviver com ela. [...] Iniciativa privada não dá segurança nenhuma. [...] Acho que eu não tenho a segurança que eu tinha na época em que eu trabalhava numa empresa estatal, eu não tenho aquela segurança mais" (funcionário de área administrativa).

Há mesmo certo reconhecimento de que todas essas mudanças propiciaram novas oportunidades no trabalho e levaram a acentuado crescimento profissional, ainda que implicando estresse e desgaste no trabalho.

"Que a gente está trabalhando mais, com certeza. Eram 6.000, hoje está com 3.000, alguém está fazendo o serviço. [...] O estresse é muito grande, mas profissionalmente eu cresci muito. Isso vale muito também" (funcionário de área administrativa). 


\section{Discussão e Conclusõos}

Embora o modelo de Rousseau (1996) para a mudança no contrato psicológico tenha sido idealizado como recomendação para a implementação bem sucedida de uma nova base no relacionamento entre empregador e empregado, tem grande utilidade na análise e interpretação de mudanças do contrato psicológico no caso de empresas privatizadas.

Para melhor visualização do processo nas duas empresas, apresenta-se, a seguir, o Quadro 1.

\section{Quadro 1: Transformação do Contrato Psicológico nas Empresas ServA e ServB}

\begin{tabular}{|l|c|c|}
\hline \multicolumn{1}{|c|}{ Etapas } & \multicolumn{1}{c|}{ ServA } & ServB \\
\hline $\begin{array}{l}\text { (1) Ameaça ao antigo } \\
\text { contrato }\end{array}$ & Privatzação iminente & Privatização iminente \\
\hline $\begin{array}{l}\text { (2) Preparação para a } \\
\text { mudança }\end{array}$ & $\begin{array}{c}\text { Palestras e seminários organizados } \\
\text { pela empresa (estatal); } \\
\text { PDV - Programa de Desligamento } \\
\text { Voluntário (privada) }\end{array}$ & $\begin{array}{c}\text { PDV - Programa de Desligamento } \\
\text { Voluntário (estatal); } \\
\text { PDI - Programa de Demissão } \\
\text { Incentivada (privada) }\end{array}$ \\
\hline $\begin{array}{l}\text { (3) Criação de um } \\
\text { novo contrato }\end{array}$ & $\begin{array}{c}\text { Novas regras de trabalho: maior } \\
\text { cobrança de resultados, horas de } \\
\text { trabalho prolongadas }\end{array}$ & $\begin{array}{c}\text { Novas regras de trabalho: forte } \\
\text { cobrança de resultados; } \\
\text { multifuncionalidade, maior autonomia, } \\
\text { horas de trabaho probngadas; } \\
\text { programas de trainee; outras ondas } \\
\text { de demissão }\end{array}$ \\
\hline $\begin{array}{l}\text { (4) Vivência no novo } \\
\text { contrato }\end{array}$ & $\begin{array}{c}\text { Perda da estabilidade do emprego; } \\
\text { preservação da relação de confança }\end{array}$ & $\begin{array}{c}\text { Vuherabilidade do contrato de } \\
\text { trabalho; acentuado crescimento } \\
\text { profissional }\end{array}$ \\
\hline
\end{tabular}

Há diferenças a serem consideradas no processo de alteração do contrato psicológico no caso das duas empresas analisadas. De forma geral, as modificações realizadas na ServB foram muito mais profundas e significativas do que na ServA.

A ServB nasceu de uma empresa estatal operacionalmente e financeiramente deficiente, com regras de trabalho baseadas em segurança no emprego, valorização da senioridade e da hierarquia e acentuada limitação de responsabilidade. Com grandes mudanças nos postos principais de comando, a nova empresa imprimiu um ritmo muito mais dinâmico, com acentuada cobrança de resultados. Para atingir os resultados esperados, demitiu, sempre que necessário, não apenas 
funcionários sem cargo gerencial, mas também diretores e gerentes. Além disso, procedeu à contratação de muitos novos funcionários, principalmente por meio de programas de trainees que, de certa forma, absorvem, de acordo com Rousseau (1996), o novo contrato psicológico de forma mais fácil, uma vez que são socializados já dentro das novas regras vigentes.

A modernização tecnológica sofreu grandes mudanças, acentuando ainda mais as modificações na forma de trabalhar, tendo ainda por conseqüência a dispensa de parte da mão-de-obra. Acresce o fato de que na Região Sul, onde a empresa opera, poucas empresas atuam no mesmo setor, limitando seriamente outras alternativas de emprego.

A ServA, por sua vez, ainda quando estatal, era considerada um modelo de eficiência operacional, tecnológica e gerencial, se comparada com outras empresas brasileiras do mesmo setor. Quando privatizada, embora passasse a fazer parte de uma holding com outras empresas do setor, passando por reestruturações e terceirização de atividades, não sofreu alterações fundamentais nos principais postos de comando. As pessoas permaneceram as mesmas, sendo que programas de trainee, na época desta pesquisa, ainda estavam em estágio incipiente.

No que se refere aos aspectos tecnológicos, a empresa já estava na vanguarda do seu setor, contando com pessoal altamente capacitado, fruto de intenso desenvolvimento de pessoal realizado ainda na época de estatal. As principais mudanças na forma de trabalhar se deram no âmbito da segurança do contrato de trabalho e da cobrança mais intensa de resultados. O mercado de trabalho, comparado com o da ServB, demandava mais intensamente a mão-de-obra especializada existente, o que oferecia, para os cargos técnicos, maiores alternativas de emprego.

Pode-se dizer, no caso das duas empresas, que a mudança do contrato psicológico foi bem sucedida, no sentido de que foi possível uma renegociação ao longo do tempo, transformando as bases de relacionamento, sem degeneração para um sentimento de violação contratual.

No caso da ServA, cujas mudanças foram menos acentuadas do que na ServB, um aspecto importante na renegociação do contrato foi a confiança preexistente entre a administração e os empregados, que se reflete no orgulho que tinham de sua empresa. A relação estabelecida ainda como estatal e que, de certa forma, continuou depois de privatizada, formou as bases para que as mudanças pudessem ser entendidas como necessárias e inevitáveis, sem sentimento de violação contratual.

A ServB, por sua vez, passou a ter a alta administração composta por pessoas novas, sem qualquer contato com a empresa estatal. No caso da ServB foram 
fundamentais para a renegociação do contrato estes itens: o significado simbólico das demissões aliado ao estágio do mercado externo de trabalho, a comunicação clara das novas exigências, a cobrança intensa de resultados, além do envolvimento da alta administração na operação da empresa.

O modelo de Rousseau (1996) permitiu o entendimento da dinâmica de transformação no caso de duas empresas privatizadas. De acordo com Robinson (1997) e com a análise dos dois casos, pode-se dizer que a renegociação do contrato psicológico requer o entendimento não apenas dos aspectos relativos às promessas - implícitas ou explícitas - percebidas pelo empregado, mas também de outros pontos externos ao contrato, como a confiança preexistente na relação empregador-empregado, a mudança do ambiente externo (competição, mercado de trabalho) e a mudança do ambiente interno (cultura organizacional, tecnologia adotada).

\section{ReferênCIAs Biblográficas}

GIL, A. C.

Métodos e técnicas de pesquisa social. São Paulo: Atlas, 1987.

HERRIOT, P.;

PEMBERTON, C.

Contracting careers. Human

Relations, v. 49, n. 6, 1996.

MORRINSON, E. W.;

ROBINSON, S.

When employees feel betrayed: a model of how psychological contract violation develops. Academy of Management Review, v. 22, n. 1, p. 226-256, 1997.
O'REILLY, B.

The new deal: what companies and employees owe one another. Fortune, June 13 1994. p.28-33.

PATTON, M. Q.

Qualitative evaluation methods. London: Sage Publications, 1980.

ROBINSON, S. L.

Violation of psychological contracts: impacts on employee attitudes. In: TETRICK, L. E.; BARLING, J. (Eds). Changing employment relations. Washington, D.C.: American Psychological Association, 1995. 
Trust and the breach of the psychological contract. Administrative Science Quarterly, v. 41, p. 574-599, 1996.

ROBINSON, S. L.;

KRAATZ, M. S.;

ROUSSEAU, D. M.

Changing obligations and the psychological contract: a longitudinal study. Academy of Management Journal, v. 37, n. 1, p. 137-152, 1994.

ROUSSEAU, D. M.

Changing the deal while keeping the people. Academy of Management Executive, v. 10, n. 1, 1996.
ROUSSEAU, D. M.;

WADE-BENZONI, K.

Changing individual-organization attachments: a two-way street. In: HOWARD, A. (Ed). The changing nature of work. London : Jossey-Bass, 1995.

YIN, R. K.

Case study research: design and methods. London: Sage Publications, 1984.

Applications of case study research. London: Sage Publications, 1993. 